•研究报告・

\title{
贵州侗族地区香禾糯品种多样性的变化
}

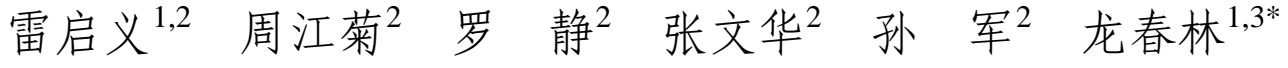 \\ 1 (中央民族大学生命与环境科学学院, 北京 100081) \\ 2 (凯里学院环境与生命科学学院, 贵州凯里 556000) \\ 3 (中国科学院昆明植物研究所, 昆明 650201)
}

\begin{abstract}
摘要: 香禾糯是侗族地区广泛种植并具有重要意义的一类糯稻农家品种。探讨香禾糯地方品种多样性变化的历史 与现实问题, 有利于及时制定与侗族地区经济和传统文化发展相适应的香禾糯种质资源保护策略和措施。本研究 运用民族植物学、文化人类学、生态学等多学科综合研究方法, 自 2005 年以来, 对贵州侗族地区香禾糯品种多样 性的变化情况进行了为期 12 年的调查和统计。结果表明, 历史上香禾糯在侗族地区的栽培和利用非常普遍, 但从 清雍正年间至新中国成立初期, 贵州侗族地区经历了3次大型的“糯改粘”运动, 导致香禾糯种植面积和品种数量 大幅度减少; 目前黎平、从江和榕江县侗族地区香禾糯品种大约为 100 个, 比 20 世纪 80 年代初调查到的 363 个品种 减少了 $72.5 \%$, 即使在黄岗、高仠等香禾糯种植传统保持相对较好的侗族村寨, 其种植面积和品种数量也减少了 $50 \%$ 以上, 而且这种减少趋势越来越严重。香禾糯品种减少的重要原因是杂交稻的大面积推广, 而近年来随着侗 族地区社会、经济和文化等方面的快速发展与变迁, 香禾糯品种多样性正在面临新一轮的冲击, 消失速度加快。 香禾糯的多样性维系与侗族的生产生活和传统文化关系密切, 需要及时采取措施加以保护。
\end{abstract}

关键词：地方品种; 侗族; 香禾糯; 变化趋势; 农业生物多样性

\section{Changes in the numbers of Kam fragrant glutinous rice varieties in the Dong regions of Guizhou Province}

\author{
Qiyi Lei ${ }^{1,2}$, Jiangju Zhou ${ }^{2}$, Jing Luo ${ }^{2}$, Wenhua Zhang ${ }^{2}$, Jun Sun ${ }^{2}$, Chunlin Long ${ }^{1,3^{*}}$ \\ 1 College of Life and Environmental Sciences, Minzu University of China, Beijing 100081 \\ 2 College of Environmental and Life Sciences, Kaili University, Kaili, Guizhou 556000 \\ 3 Kunming Institute of Botany, Chinese Academy of Sciences, Kunming 650201
}

\begin{abstract}
The Kam (Dong people) fragrant glutinous rice is a group of sticky rice varieties, which have been widely cultivated in Dong areas with great success. Revealing the history and status of the diversity of Kam fragrant glutinous rice is helpful for the timely identification of conservation strategies and implementation plans for preserving these germplasm resources, with respect to the economic development and traditional culture in Dong ethnic areas. The authors and their collaborators carried out research on germplasm diversity of Kam fragrant glutinous rice in Dong areas of Guizhou for 12 years using multiple approaches including ethnobotany, cultural anthropology, and ecology. Results showed that Kam fragrant glutinous rice has been widely grown in the Dong areas for many years. From the beginning of the Yongzheng period of the Qing Dynasty to the foundation of New China, the Dong areas of Guizhou have suffered three large-scale movements transforming glutinous rice into non-glutinous rice, which resulted in greatly reduced plantation areas of Kam fragrant glutinous rice and the number of landraces. At present, there are about 100 glutinous rice landraces in Congjiang, Liping, and Rongjiang counties, a decrease of $72.5 \%$ as compared to the 363 landraces investigated in the early 1980s. Even in the Dong villages such as Huanggang and Gaoqian where the Kam fragrant glutinous rice landraces have been maintained carefully, their plantation areas and landrace
\end{abstract}

收稿日期: 2017-04-13; 接受日期: 2017-06-30

基金项目: 国家自然科学基金(31360070, 31161140345, 3171101235)、国家科技计划项目(2012FY110300)、贵州省自然科学基金(20102078)、贵州省自 然科学联合基金(LKK2013-05, LH2015-7752)、贵州省教育厅自然科学项目基金(20090082)、贵州省教育厅社科基金(S2008042)、中央民族大学学术团 队建设项目(2015MDTD16C, ydzxxk201618)、2012 环境保护部南京环境科学研究所地方遗传资源调查项目和 2017 年贵州省教育厅创新群体项目。

* 通讯作者 Author for correspondence. E-mail: long@mail.kib.ac.cn 
numbers have been reduced by more than $50 \%$, and this trend is becoming more and more evident. The expansion of hybrid rice over a large scale has greatly influenced the reduction of local landraces. Especially in recent years, the rapid development and transition of social, economic, and cultural aspects of the Dong communities have threatened the Kam fragrant glutinous rice landraces, which are quickly disappearing. The maintenance of the diversity of varieties of Kam fragrant glutinous rice was closely related to the production, life, and traditional culture of the Dong people. It is, therefore, necessary to adopt strategies and measures suitable for the development of the economy and traditional culture for the conservation of these plants in Dong ethnic areas.

Key words: landraces; Dong people; glutinous rice; changing trend; agrobiodiversity

全球一半以上人口的食物来源于水稻(Oryza sativa) (Babu et al, 2014), 水稻被认为是世界上最 重要的农作物之一(Chappell \& Lavalle, 2011)。近年 来的大量研究表明, 边远欠发达少数民族地区的水 稻品种多样性极为丰富, 如中国的云南和贵州(Gao, 2003; Cui et al, 2016)、印度东北部(Hore, 2005)、泰 国的北部(Akimoto et al, 1999)、尼泊尔(Bajracharya et al, 2010)、尼日尔(Sow et al, 2014)等地区, 在维持 当地的农业生物多样性方面起着非常重要的作用, 特别是水稻种质资源多样性的综合性利用与病虫 害防治等方面的作用非常明显, 已经得到了实践证 明(Zhu et al, 2000; Leung et al, 2003)。然而, 随着人 口膨胀、环境恶化、经济发展不平衡、传统耕作制 度变迁等, 水稻等重要作物的遗传资源不断枯竭, 特别是我国和东南亚经济迅速发展的国家如泰国、

马来西亚、印度以及越南等, 少数民族地区的水稻 多样性消失现象尤为突出(卢宝荣, 1998), 农业生物 多样性正在遭受前所未有的破坏, 地方稻种基因资 源大量流失(卢宝荣, 1998)。因此, 如何保护和利用 水稻、小麦等重要的传统农作物品种, 实现农业生 物多样性的可持续发展, 已经成为当今世界发展亟 待解决的重要问题(Thrupp, 2000; Temudo, 2011)。

糯禾是贵州、湖南、广西三省交界一带侗族、 苗族等少数民族在长期的生产实践中选育并传承 至今的一类特殊水稻农家品种(或称地方品种), 属 于粳型糯稻。“香禾糯” 是侗族对糯性禾类谷物的统 称, 本地区的传统糯稻品种包含大量的香禾糯品 系。香禾糯除了在湖南的通道县和广西的龙胜县、 三江县有部分侗族村寨种植以外, 主要分布在贵州 东南部的黎平、从江和榕江三县的侗族社区, 侗语 统称为Oux或Kgoux, 常被译为Kam rice of China或 Kam sweet rice (Voeks, 2007)。

香禾糯具有多种生态类型, 对病虫害具有较强
的抗性，广泛适应于侗族地区复杂的自然环境，特 别适应于高山阴冷和贫痊环境。香禾糯米饭清香可 口，素有 “一家煮饭百家香”的美誉，历来深受侗族 人民的喜爱。黔东南地区种植糯稻已有悠久的历史 (严奇岩, 2008; 贵州通史编委会, 2012; 杨筑慧, 2014), 如今糯食文化在黔东南地区依然非常盛行, 侗族香禾糯的农耕文化就是很好的证明(杨黎等, 2008)。侗民族的生老病死都与香禾糯有着千丝万缕 的联系，香禾糯在侗族社区的生产实践与精神文化 等方面具有重要的地位(雷启义等, 2013)。侗族地区 的“稻-鱼-鸭系统”(稻种主要为香禾糯)已经被列为 全球重要农业文化遗产。

围绕香禾糯种质资源的遗传多样性保护与利 用问题已经开展了一些研究工作(Jiao et al，2011; 蒲琨等, 2012; Wang et al, 2016)。然而，以往的研究 多是进行一些村寨的香禾糯种质的收集，仅仅就 一两个县的少部分村寨的种质资源进行过多样性 的标记和比较研究(余显权等, 2005; 马琳等, 2010), 并且集中在生态与文化相关的问题以及品质性状 等方面(郑晓峰等，2010; 吴元华等，2010; 潘永荣 和龙宇晓, 2013), 很少关注该地区香禾糯遗传资源 消失这一问题。近十多年来, 我们通过民族植物 学、文化人类学和生态学等方法调查和研究发现, 由于杂交稻的推广和环境、经济、文化等因素的影 响，黔东南侗族社区香禾糯的多样性正在快速消 失。为了及时有效地保护当地香禾糯品种的多样性, 需要全面认识侗族地区香禾糯品种多样性变化的 历史与现状，制定适合侗族地区社会、经济和民族 文化发展的种质资源保护措施。

\section{1 研究地概述和研究方法}

\section{1 研究地区}

黔东南苗族侗族自治州位于贵州东南部，与湖 
南和广西毗邻, 有苗族、侗族等十多个世居民族。 2015年全州总人口约 450 万, 少数民族占全州人口 总数的 $82 \%$, 其中苗族人口占 $42 \%$, 侗族人口约占 $32 \%$ 。黔东南的侗族主要分布于黎平、从江、榕江、 天柱、锦屏等相连的几个县, 其中以黎平、从江、 榕江三县交界处的侗寨较为集中, 这一带也是香禾 糯传统品种较为丰富的地区。这一区域几乎全是山 地, 森林覆盖率达 $80 \%$ 以上。在历史上交通极为落 后, 但近 10 年来, 机场、高速公路、高速铁路、高 等级乡村公路陆续建成, 当地经济得到了快速发展, 已经成为民族生态文化旅游的热点地区。

\section{2 研究方法}

主要采用了民族植物学、文化人类学、生态学 等学科的综合方法, 通过查阅相关的文献资料、实 地走访调查侗族社区的生产、生活以及社会文化与 习俗, 通过半结构式访谈、关键人物访谈、参与式 调查等方法, 全面收集相关资料与信息, 最后汇总 统计分析。

(1)文献收集: 本研究的地方志资料主要来自 黔东南州图书馆和凯里学院图书馆的特色馆, 期刊 文献主要来源于维普数据库和Web of Science。重点 查阅了本地区地方志的相关农史资料和公开发表 的相关文献, 同时深入该地区州、县、乡镇的农业 管理部门和村委会查阅2000-2015年的统计资料, 了解香禾糯的历史背景与现实耕作情况等。

(2)实地调查: 2005年9月至2016年, 团队每年 都在黔东南主产香禾糯的侗族社区 (从江、榕江、黎 平、天柱和锦屏侗族主要聚居社区) 开展为期 2 个月 左右的调查, 主要通过半结构式访谈、关键人物访 谈、参与式调查等综合方法考察了 42 个侗族村寨。 每个村寨调查20-30\%的农户, 受访村民年龄范围 从18-89岁, 男女比例各占50\%左右。半结构式访谈 主要涉及农户香禾糯品种的种植管理与在传统文 化方面的利用情况、家庭经济收入与外出务工情 况、特殊品种资源的利用信息(环境适应与病虫害防 治)等内容(附录1); 关键人物访谈主要对象为寨老、 村领导、歌师、祭师等, 旨在了解香禾糯的种植历 史和传统文化利用情况以及品种变化的相关信息; 参与式调查主要是深入田间地头、农户和村寨, 与 村民一起收集和了解香禾糯的品种资源, 特别是品 种的分类与鉴定工作。此外, 通过问卷调查了该地 区在2004年以前各个村寨的记忆品种与利用情况。
选择香禾糯耕作制度与民族传统文化保持较 好的、调查资料和信息较完整、人口较多、香禾糯 品种资源较丰富的黄岗、占里、小黄、岩洞、坑洞 和高仟 6 个侗寨进行重点分析。通过上述方法了解 与香禾糯种质资源相关的侗族传统耕作、历史、信 仰、习俗、文学、艺术等民族传统文化以及经济发 展状况, 从历史与现实两个方面来深入探讨香禾糯 品种在侗族地区的变化情况。

\section{3 品种的收集与鉴定}

品种收集主要采用以下3种方式: (1)深入田间 地头调查香禾糯的种植情况并采集样本; (2)秋收后 到农户家的禾架与禾昌调查收集; (3)通过每个自 然村寨集体征集的方式收集村寨里的所有香禾糯 品种。

品种的民间分类方法: 首先由种植香禾糯农户 识别, 其次由本村寨老或村干部识别, 最后通过相 邻村寨之间的普通村民、寨老或村干部集中比较识 别后进行鉴定。参与本项目品种集中识别的村民来 自黄岗、占里、小黄、岜扒、高增、银潭、高仟、 四寨、坑洞、岩洞、竹坪、肇兴、铜关共 13 个村, 每 村 2 名共 26 人(男 19 人, 女 7 人), 年龄为 $50-83$ 岁。最 后合并同种异名, 分开同名异种, 依据民间分类确 定品种数量。

\section{4 数据处理与分析}

利用 Microsoft Excel 2007 软件对历史文献中 香禾糯品种数、2000-2015 年 6 个侗寨外出务工和 各村的香禾糯品种的调查数据进行处理和统计, 生 成相关的图表并进行对比分析。

\section{2 结果}

\section{1 黔东南地区糯稻的重要地位}

调查结果表明, 黔东南地区少数民族繁多的传 统节日、婚丧嫁娶和礼仪习俗中都要用到糯米。他 们认为自己的祖先在古代是种植糯稻和食用糯米 的，至今在人去世后都在逝者的手或胸口上放上糯 米饭或糯米团, 作为死者认祖归宗的信物。说明了 黔东南先民们远古时候主要种植糯稻。调查还发现, 在黔东南苗族、侗族等少数民族的古歌、古词、迁 徙词、民间故事和传说等文学艺术作品中都能找到 与糯米相关的内容, 这说明糯稻在该地区民族的生 产生活和传统文化中具有非常重要的地位。 


\section{2 黔东南地区与侗族主要居住县的香禾糯种植 面积变化}

黔东南的世居少数民族都没有自己的文字, 有 关糯稻种植的具体历史资料不多见。通过查阅《贵 州通史》(贵州通史编委会, 2012)、《黔东南地方志》 (黔东南苗族侗族自治州地方志编纂委员会, 1993) 以及近期的研究文献(严奇岩, 2008; 杨筑慧, 2014), 结果表明: 在明朝和清朝时期黔东南地区糯稻的种 植比例非常高, 但是从清朝开始到新中国成立初期, 经历3次 “糯改粘”运动后, 糯稻种植比例锐减到了 总种植面积的 $23 \%$ (表1)。从新中国成立到1990年这 段时间糯稻种植面积变化不明显, 但从1990-2010 年的20年时间里, 糯稻种植面积减少到 $7 \%$, 与明清 时期相比已经大幅度减少。

黎平县和从江县是侗族的主要聚居县, 大部分 侗寨仍然保持着香禾糯的传统耕作文化。新中国成 立以后关于香禾糯种植情况, 两县都有比较具体的 记录(这两个县种植的糯稻几乎全部为香禾糯)(程 良炳, 1981; 黔东南苗族侗族自治州地方志编纂委 员会, 1993; 严奇岩, 2008; 龙初凡和孔蓓, 2012; 杨 筑慧, 2014)。从新中国成立初期到2015年, 两县的 香禾糯种植面积均急剧减少(表1), 百分比分别从 $80 \%$ 和 $82 \%$ 减少到 $2 \%$ 和 $6 \%$ 。1962年黎平县香禾糯种 植面积突然回升(46\%), 是由于地方政府之前推行
“糯改粘”后, 新品种的籼稻因不适应山区环境减产 而遭到农民反对后又恢复种植香禾糯; 1963年当地 政府又强行推广籼稻种植, 使香禾糯种植面积再次 下降到6\%。从江县在1980-1991年香禾糯种植面积 出现回升, 是由于改革开放后农民家庭自由选择种 植品种, 所以香禾糯又恢复了一定的种植面积。

\section{3 香禾糯品种快速减少}

\subsection{1 黎平县、从江县、榕江县香禾糯品种调查}

关于香禾糯种类的历史记载较早的文献是光绪 辛卯年(1891年)新修订的《黎平府志》, 记载黎平县 有秃头禾、冷水禾、红米禾等50个品种左右(程良 炳，1981)。新中国成立以后分别于1958年、1974 年和1979年在黔东南地区进行过3次大的普查, 共 统计有399个糯稻品种(大部分为香禾糯) (黔东南 州地方志编纂委员会, 1993)。1980年对香禾糯主 要种植区的黎平、从江和榕江三县进行调查, 统计 到的香禾糯有363个品种(表3) (吴祥厚, 1981)。

2005年以来, 我们团队对侗族主要聚居的黎 平、从江、榕江、天柱和锦屏 5 县进行了调查, 发现 天柱、锦屏县等北侗民族地区以杂交糯稻种植为主, 香禾糯种植已经很少见, 而黎平、从江、榕江三县 交界的南侗民族地区还在普遍种植香禾糯。在此期 间, 我们对侗族地区36个主要村寨进行了全面的调 查, 采集到368号标本(存放于凯里学院香禾糯种质

\section{表1 黔东南历代粘稻与糯稻种植面积比例 $(\%)$}

Table 1 Proportion of plantation areas of no-glutinous rice and glutinous rice in southeast Guizhou

\begin{tabular}{|c|c|c|c|c|}
\hline 时间 Time & 粘稻 No-glutinous rice (\%) & 糯稻 Glutinous rice (\%) & 重要事件 Notable event & 数据来源 Data source ${ }^{*}$ \\
\hline $\begin{array}{l}\text { 明朝时期 } \\
\text { Ming Dynasty }\end{array}$ & 少量的 Small amount & 大量的 Large amount & & (1) \\
\hline $\begin{array}{l}\text { 清朝时期 } \\
\text { Qing Dynasty }\end{array}$ & 40.0 & 60.0 & $\begin{array}{l}\text { 糯改粘期 } 1 \\
\text { The first stage of substitute no-glutinous } \\
\text { rice for glutinous rice }\end{array}$ & (1) \\
\hline $\begin{array}{l}\text { 民国时期 } \\
\text { Republican period }\end{array}$ & 60.0 & 40.0 & $\begin{array}{l}\text { 糯改粘期 } 2 \\
\text { The second stage of substitute } \\
\text { no-glutinous glutinous rice for glutinous } \\
\text { rice }\end{array}$ & (1) \\
\hline $\begin{array}{l}\text { 建国初期 } \\
\text { Early time of New } \\
\text { China }\end{array}$ & 77.0 & 23.0 & $\begin{array}{l}\text { 糯改粘期 } 3 \\
\text { The third stage of substitute no-glutinous } \\
\text { rice for glutinous rice }\end{array}$ & (2) \\
\hline 1990 & 81.0 & 19.0 & & (3) \\
\hline 2000 & 90.0 & 10.0 & & (4) \\
\hline 2010 & 93.0 & 7.0 & & (4) \\
\hline
\end{tabular}

(1)来源于《贵州通史》(贵州通史编委会, 2012); (2)来源于文献《黔东南苗族侗族自治州农业志》(黔东南苗族侗族自治州地方志编纂委员会, 1993)和相关研究文献(严奇岩, 2008; 杨筑慧, 2014); (3)(4)数据由黔东南州农业部门提供。

(1) Cited from The integrity Guizhou History (The Editorial Board of Integrity Guizhou History, 2012); (2) Cited from Qiandongnan Miao and Dong Autonomous Prefecture Agriculture Chronicles (The Compilation Committee of Local Chronicles of Qiandongnan Miao and Dong Autonomous Prefecture, 1993; Yan, 2008; Yang, 2014); (3)(4) Provided by the Department of Agriculture of Qiandongnan Autonomous Prefecture. 
表2 黎平县和从江县历代糯稻种植面积比例

Table 2 Proportion of plantation areas of glutinous rice in Liping and Congjiang counties

\begin{tabular}{|c|c|c|c|c|c|}
\hline \multicolumn{3}{|c|}{ 黎平县 Liping County } & \multicolumn{3}{|c|}{ 从江县 Congjiang County } \\
\hline $\begin{array}{l}\text { 时间 } \\
\text { Time }\end{array}$ & $\begin{array}{l}\text { 粘稻 } \\
\text { No-glutinous } \\
\text { rice (\%) }\end{array}$ & $\begin{array}{l}\text { 糯稻 } \\
\text { Glutinous } \\
\text { rice (\%) }\end{array}$ & $\begin{array}{l}\text { 时间 } \\
\text { Time }\end{array}$ & $\begin{array}{l}\text { 粘稻 } \\
\text { No-glutinous } \\
\text { rice (\%) }\end{array}$ & $\begin{array}{l}\text { 糯稻 } \\
\text { Glutinous } \\
\text { rice (\%) }\end{array}$ \\
\hline 1949 & 20.0 & 80.0 & 1955 & 18.0 & 82.0 \\
\hline 1958 & 80.0 & 20.0 & 1962 & 62.0 & 38.0 \\
\hline 1962 & 54.0 & 46.0 & 1980 & 45.0 & 55.0 \\
\hline 1963 & 94.0 & 6.0 & 1991 & 51.0 & 49.0 \\
\hline 1973 & 71.0 & 29.0 & 1995 & 72.0 & 28.0 \\
\hline 1980 & 83.0 & 17.0 & 2000 & 88.0 & 12.0 \\
\hline 2005 & 80.0 & 20.0 & 2005 & 87.0 & 13.0 \\
\hline 2010 & 90.0 & 10.0 & 2010 & 89.0 & 11.0 \\
\hline 2013 & 97.0 & 3.0 & 2013 & 91.0 & 9.0 \\
\hline 2015 & 98.0 & 2.0 & 2015 & 92.0 & 6.0 \\
\hline
\end{tabular}

(1) 2005 年以前两县的数据来源于本地的历史资料和相关研究文献 (程良炳, 1981; 黔东南苗族侗族自治州农业志编委会, 1993; 严奇 岩, 2008; 龙初凡和孔蓓, 2012; 杨筑慧, 2014), 两县普遍种植的糯 稻主要是香禾糯, 文献中有些部分把糯稻与香禾糯等同; (2) 2005年 以后的数据由所属县的农业主管部门提供, 仅指糯稻种植面积, 不 包括杂交糯稻; (3)两县有关香禾糯种植面积的年代统计信息有限, 时间不连续, 表中的时间也不完全同步。

(1) Before 2005, the data of two counties come from the local literatures (Cheng, 1981; Qiandongnan Miao and Dong Autonomous Prefecture Agriculture Chorography, 1993; Yan, 2008; Long and Kong, 2012; Yang, 2014). The counties commonly grown glutinous rice is mainly Kam fragrant glutinous rice, some part of the glutinous rice were equated with Kam fragrant glutinous rice in the literatures. (2) The data were provided by the agriculture authority of the counties after 2005. (3) The time is not continuous because of the limited statistical information of Kam fragrant glutinous rice in the counties, so the time is not fully synchronized in the Table.

库), 经侗寨部分村民初步辨认, 再由各个自然村寨 对本村的品种进行鉴定，最后组织13个侗族村寨的 寨老或村领导 26 人对采集到的所有村寨的品种集
中进行鉴定与分类，将同名异种分开或异种同名合 并以后，认为2000-2015年这段时间，黔东南侗族 地区香禾糯品种有102个，明显少于1980年调查统 计到的363个品种(吴祥厚, 1981) (表3), 整个地区的 香禾糯品种数量已减少了 $72.5 \%$ 。

\subsection{2 主要侗族村寨的香禾糯品种变化及其趋势}

2000-2015年，对香禾糯传统耕作文化保持较 好的 6 个侗族村寨的香禾糯品种跟踪调查(表4)。结 果表明, 各个村寨在历史上都曾经种植过非常丰富 的香禾糯品种, 除了小黄村以外, 各个村都超过了 20 个品种; 但随着时间的推移, 每个村寨的品种 无一例外地递减, 15 年后, 品种数量的减少都超过 了 $50 \%$ 。

综合表3和表4的数据可见, 1981-2015年, 黔东 南从江、黎平和榕江主要侗族地区香禾糯品种由 363 个减少到了 102 个, 品种数减少了 $71.9 \%$ 。 2000-2015年, 6个代表性村寨的香禾糯品种总数 由 98 个减少到 48 个, 品种数减少了 $51.0 \%$ 。这些数 据说明香禾糯品种正在急剧减少，而且有加快的 趋势。

\section{4 侗寨外出务工与香禾糯品种变化的相关性}

对6个自然村寨2000-2005年外出务工跟踪调 查统计 (见表5, 其中 2000 年的外出务工数据为各村 委会以及部分年长者的受访者回忆口述提供), 结 果显示: 2000-2015年, 6个村寨外出务工人数逐年 增加，到2015年，除了黄岗村仅有 $9.2 \%$ 的人外出务 工外, 其余 5 个村外出务工人数几乎都超过了 $20 \%$, 其中岩洞村外出的比例最高(为 $24.0 \%$ ), 外出务工 的比例平均为 $21.8 \%$ 。黄岗村至今仍然保存和延续

表3 1981年和2015年黎平县、从江县、榕江县“禾”品种数

Table 3 Number of “He” landraces in Liping, Congjiang and Rongjiang counties in 1981 and 2015

\begin{tabular}{|c|c|c|c|c|c|c|}
\hline 时间 Time & \multicolumn{2}{|l|}{ 类别 Category } & $\begin{array}{l}\text { 黎平县 } \\
\text { Liping County }\end{array}$ & $\begin{array}{l}\text { 榕江县 } \\
\text { Rongjiang County }\end{array}$ & $\begin{array}{l}\text { 从江县 } \\
\text { Congjiang County }\end{array}$ & \multirow{2}{*}{$\begin{array}{l}\text { 合计 } \\
\text { Total } \\
20\end{array}$} \\
\hline \multirow[t]{5}{*}{1981} & \multirow[t]{2}{*}{ Aquatic He } & 粘 Non-glutinous & 2 & 4 & 14 & \\
\hline & & 糯 Glutinous & 29 & 81 & 239 & 349 \\
\hline & \multirow[t]{2}{*}{ 旱禾 Xerophytic He } & 粘 Non-glutinous & 1 & & & 1 \\
\hline & & 糯 Glutinous & & 6 & 8 & 14 \\
\hline & \multicolumn{2}{|c|}{ 香禾糯 Fragrant glutinous } & 29 & 87 & 247 & 363 \\
\hline \multirow[t]{5}{*}{2015} & \multirow[t]{2}{*}{ 水禾 Aquatic $\mathrm{He}$} & 粘 Non-glutinous & 2 & 1 & 2 & 5 \\
\hline & & 糯 Glutinous & 37 & 6 & 55 & 98 \\
\hline & \multirow[t]{2}{*}{ 旱禾 Xerophytic He } & 粘 Non-glutinous & 1 & & & 1 \\
\hline & & 糯 Glutinous & & 2 & 2 & 4 \\
\hline & \multicolumn{2}{|c|}{ 香禾糯 Fragrant glutinous } & 37 & 8 & 57 & 102 \\
\hline
\end{tabular}

1981年的数据来源于吴祥厚(1981) Data for 1981 are adopted from Wu (1981) 
表4 2000-2015年6个主要侗族村寨香禾糯品种数的变化

Table 4 Changes of number of glutinous rice landraces in six main Dong villages from 2000 to 2015

\begin{tabular}{lllllllll}
\hline $\begin{array}{l}\text { 村寨 } \\
\text { Village }\end{array}$ & $\begin{array}{l}\text { 记忆品种 } \\
\text { Memory variety }\end{array}$ & 2000 & 2005 & 2007 & 2009 & 2011 & 2013 & 2015 \\
\hline 黄岗村 Huanggang & 29 & 22 & 20 & 21 & 17 & 16 & 15 & 12 \\
坑洞村 Kengdong & 21 & 15 & 10 & 10 & 8 & 8 & 7 & 7 \\
岩洞村 Yandong & 23 & 16 & 11 & 8 & 7 & 7 & 6 & 5 \\
小黄村 Xiaohuang & 18 & 11 & 9 & 8 & 7 & 7 & 7 & 5 \\
占里村 Zhanli & 22 & 13 & 11 & 10 & 10 & 9 & 7 & 6 \\
高任村 Gaoqian & 27 & 21 & 18 & 18 & 18 & 18 & 16 & 13 \\
总数 Total & 140 & 98 & 79 & 75 & 67 & 65 & 58 & 48 \\
\hline
\end{tabular}

* 记忆品种是指该村寨曾经种植过的香禾糯品种或类型 Memory varieties are varieties or type of glutinous rice landraces that had been grown in the villages

表5 主要侗族社区外出务工人数统计

Table 5 Investigation of migrant worker population in six main Dong villages

\begin{tabular}{|c|c|c|c|c|c|c|c|c|c|}
\hline \multirow{2}{*}{$\begin{array}{l}\text { 村寨 } \\
\text { Village }\end{array}$} & \multirow{2}{*}{$\begin{array}{l}\text { 人口 } \\
\text { Population }\end{array}$} & \multicolumn{2}{|l|}{ 2000年 } & \multicolumn{2}{|l|}{ 2005年 } & \multicolumn{2}{|l|}{ 2010年 } & \multicolumn{2}{|l|}{ 2015年 } \\
\hline & & $\begin{array}{l}\text { 外出人数 } \\
\text { Migrant } \\
\text { number }\end{array}$ & $\begin{array}{l}\text { 百分比 } \\
\%\end{array}$ & $\begin{array}{l}\text { 外出人数 } \\
\text { Migrant } \\
\text { number }\end{array}$ & $\begin{array}{l}\text { 百分比 } \\
\%\end{array}$ & $\begin{array}{l}\text { 外出人数 } \\
\text { Migrant } \\
\text { number }\end{array}$ & $\begin{array}{l}\text { 百分比 } \\
\%\end{array}$ & $\begin{array}{l}\text { 外出人数 } \\
\text { Migrant } \\
\text { number }\end{array}$ & $\begin{array}{l}\text { 百分比 } \\
\%\end{array}$ \\
\hline 黄岗村 Huanggang & 1,200 & 30 & 2.5 & 56 & 4.7 & 77 & 6.4 & 110 & 9.2 \\
\hline 坑洞村 Kengdong & 1,500 & 60 & 4.0 & 120 & 8.0 & 150 & 10.0 & 350 & 23.3 \\
\hline 岩洞村 Yandong & 6,500 & 300 & 4.6 & 620 & 9.5 & 970 & 14.9 & 1,560 & 24.0 \\
\hline 小黄村 Xiaohuang & 3,000 & 150 & 5.0 & 230 & 7.7 & 450 & 15.0 & 670 & 22.3 \\
\hline 占里村 Zhanli & 791 & 20 & 2.5 & 45 & 5.7 & 95 & 12.0 & 170 & 21.5 \\
\hline 高仟村 Gaoqian & 1,607 & 60 & 3.7 & 140 & 8.7 & 190 & 11.8 & 320 & 19.9 \\
\hline 总计 Total & 14,598 & 620 & 4.2 & 1,211 & 8.3 & 1,932 & 13.2 & 3,180 & 21.8 \\
\hline
\end{tabular}

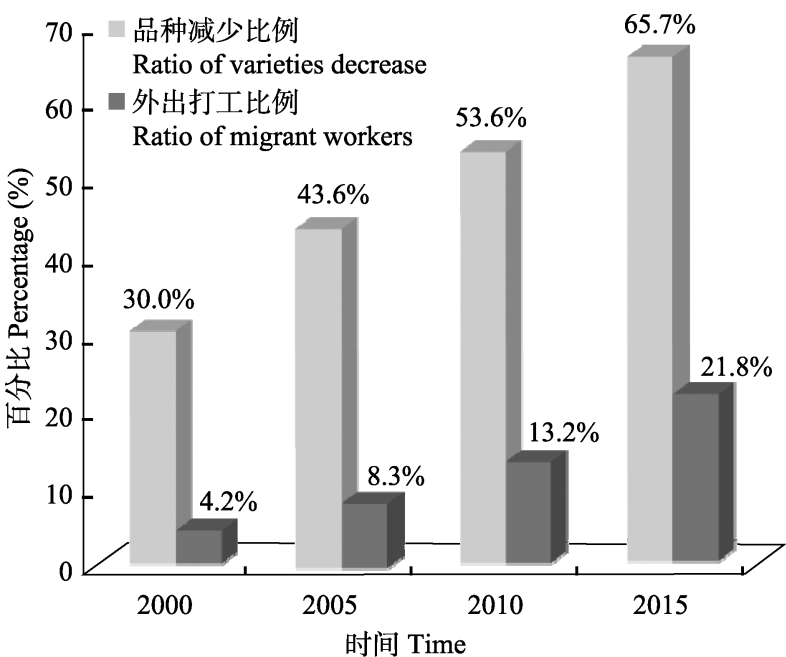

图1 侗寨外出务工与香禾糯品种变化的相关性

Fig. 1 The relationship between landrace decrease rate and ration of migrant workers

着千百年来侗族的传统生产生活习俗。2014年黄岗 村未通公路之前和外界联系不多, 长期以来过着自 给自足的农耕生活, 外出的人很少。村民们认为外
出务工很难解决主食香禾糯的问题，因而不愿外出 务工, 所以比例最低。岩洞村是镇政府所在地, 因 为交通便利，而且受主流文化的影响较大，全村外 出的人口所占比例最大。调查发现, 随着各村寨青 壮年外出务工人员的不断增加, 各村偏远的农田大 量闲置或种植杉树等经济效益显著的林木，放弃传 统的香禾糯耕作。6个传统侗寨4年中, 外出务工人 员和香禾糯品种变化的关系如图1所示：随着打工 人员比例数的逐年增加, 6 个村寨香禾糯品种减少 的比例也不断升高。

\section{3 讨论}

\section{1 黔东南糯稻品种多样性的存在基础}

黔东南是以山地为主的苗族、侗族等多个少数 民族聚居区。千百年来，各民族为适应该地区复杂 的自然环境聚族而居并在以糯稻为中心的生产生 活实践中形成了独特的糯文化，培养了一系列的糯 稻品种。据我们调查发现, 全州一年里有大小不同 
的民族传统节日 300 多个，几乎每个节日里，少数 民族都有吃糯米的习俗, 糯米在他们的婚丧嫁娶和 礼仪习俗中也不可缺少, 甚至作为重要的传统医药 使用, 可以说他们的一生中都离不开糯米(雷启义 等, 2009)。大量的研究也表明, 香禾糯在黔东南种 植具有悠久的历史, 并与该地区少数民族的传统文 化息息相关(杨黎等, 2008; 雷启义等, 2009; 焦爱霞 等, 2015; Wang et al, 2016), 这是糯稻品种的多样性 在黔东南存在的重要基础。至今该地区各少数民族 家家户户每年都有种植一定量糯稻的习惯, 特别是 在苗族和侗族地区的许多传统村落, 仍然保存着较 大面积的香禾糯种植和品种的多样性。可见, 民族 传统文化对于保护和维系香禾糯种质多样性具有 积极的意义。

\section{2 侗族地区香禾糯种植面积和品种的变化及其} 原因

贵州侗族地区在历史上广泛种植品种丰富的 香禾糯, 但近 30 年以来, 其种植面积和品种数量减 少非常明显, 既有历史的原因也有现实的原因:

(1)历史原因: 自从明清时期在贵州推行改土 归流和屯田制度后, 汉族移民不断进入黔东南少数 民族地区, 带来了新的籼稻品种和耕作技术与制度, 在一定程度上促进了经济发展。但随之而来的3次 大的“糯改粘”运动使黔东南少数民族地区千百年的 传统糯稻耕作文化受到了极大的冲击, 从根本上动 摇了糯稻的主体地位, 使黔东南地区香禾糯种植面 积大幅度减少, 但对品种数量的影响并不明显。新 中国成立后, 当地政府为了提高粮食产量, 解决贫 困山区民族的温饱问题而全面推行籼稻种植, 使黔 东南地区的香禾糯种植面积和品种都急剧减少。特 别是从1958-2005年, 由于大跃进运动影响以及后 期每户必须在国庆节前上缴全年粮食的20-30\%作 国家的公余粮, 很多在国庆节后才成熟的以及产量 相对较小的传统香禾糯品种被淘汰, 农民们纷纷改 种成熟早、产量高的籼稻。到20世纪80年代中后期, 杂交稻在侗族地区已经大面积推广, 传统的香禾糯 品种也逐步被糯性杂交稻取代, 这是香禾糯在该地 区种植面积和品种减少的最直接原因。此外, 由于 20 世纪60年代前后侗族地区木材的大量砍伐, 山区 环境恶化, 病虫害爆发, 这也是香禾糯在这一地区 种植面积减少的重要原因。
(2)现实原因: 历史上整个黔东南侗族地区交 通极为不便, 自从2005年贵州黎平县机场正式通航 后, 短短的10年内交通条件发生了翻天覆地的变 化。2011年夏蓉高速黎平至榕江段开通，2014年贵 广高铁榕江、黎平、从江段通车, 2015年黎平、从 江、榕江三县高速互通, 同年三县的乡村路路通工 程全面建成, 使这些地区成为国内外知名的民族生 态文化热点旅游区。随着交通极大的改善、网络信 息普及、国内外大量游客进出苗乡侗寨, 传统的农 耕生活已经无法满足山区侗族人民物质、精神以及 文化等方面的需要, 越来越多的侗族中青年外出学 习和务工, 在家务农的大多为 60 岁以上的老年人, 他们仅仅能耕作和管理附近的农田, 边远和高山的 农田大片闲置或进行了造林, 很多适应高山和林区 阴冷等恶劣环境的香禾糯品种渐渐地被遗弃。外出 务工的侗族青年, 饮食结构与外界日趋同化, 不再 以香禾糯作为主食, 也不再对传统文化与习俗有强 烈的依赖性。这些都使得香禾糯种质资源面临着空 前危机。

\section{3 糯稻品种多样性的保护}

香禾糯是黔东南地区侗族人民千百年来选育 出的具有很好抗病性和适应特殊环境的珍贵地方 水稻品种。政府和相关的组织及侗族学者认识到香 禾糯品种的重要价值和面临消失的危险, 近年来在 黎平县岩洞、坑洞、黄岗等侗族社区为恢复和推广 香禾糯的种植付出了诸多努力, 在多个侗寨建立了 有机种植基地, 还为香禾糯申请了 “中华人民共和 国地理标志保护产品” 称号, 开展了就地保护和迁 地保护工作。但是这些措施仍然没有明显减缓香禾 糯品种消亡的步伐, 可能的原因是没有处理好传统 耕作文化保护与当地侗族经济发展的矛盾。之所以 长期以来的 “糯改粘” 的推行和杂交稻的大力推广并 没有使香禾糯在侗族地区完全被取代, 很大程度上 是由于香禾糯在侗族传统的生产、生活与文化习俗 中的核心地位和重要作用(雷启义和周江菊, 2009)。 因此, 香禾糯种质资源的农家保护不能脱离侗族传 统文化和和经济发展的重要基础, 需要正确认识和 处理好民族传统文化、农户经济发展和香禾糯种质 资源保护的关系，创新利用民族民族传统文化保护 地区作物资源多样性的新型农家保护模式, 以便更 有效保护珍贵的糯稻地方品种。 
致谢: 黎平、从江、榕江等县农业部门和黔东南州 农业局提供了部分数据, 黄岗、小黄、岩洞、高仠、 占里等乡村侗族父老乡亲十多年来支持和帮助完 成了大量繁重的调查工作, 凯里学院部分师生长期 参与了调查研究工作, 在此一并表示感谢。

\section{参考文献}

Akimoto M, Shimamoto Y, Morishima H (1999) The extinction of genetic resources of Asian wild rice, Oryza rufipogon Griff.: a case study in Thailand. Genetic Resources and Crop Evolution, 64, 419-425.

Babu BK, Meena V, Agarwal V, Agrawal PK (2014) Population structure and genetic diversity analysis of Indian and exotic rice (Oryza sativa L.) accessions using SSR markers. Molecular Biology Reports, 41, 4329-4339.

Bajracharya J, Rana RB, Gauchan D, Sthapit BR, Jarvis DI (2010) Rice landrace diversity in Nepal: socio-economic and ecological factors determining rice landrace diversity in three agro-ecozones of Nepal based on farm surveys. Genetic Resources and Crop Evolution, 57, 1013-1022.

Chappell MJ, Lavalle LA (2011) Food security and biodiversity: can we have both? An agroecological analysis. Agriculture and Human Values, 28, 3-26.

Cheng LB (1981) Landrace rice's characteristics and utilization suggestions. Guizhou Agricultural Sciences, (2), 23-27. (in Chinese) [程良炳 (1981) 地方稻种一一禾的特点及其利 用意见. 贵州农业科学, (2), 23-27.]

Cui D, Li J, Tang C, Ai X, Yu T, Ma X, Zhang E, Cao G, Xu F, Qiao Y, Dai LY, Han LZ (2016) Diachronic analysis of genetic diversity in rice landraces under on-farm conservation in Yunnan, China. Theoretical and Applied Genetics, 129, $155-168$.

Gao LZ (2003) The conservation of Chinese rice biodiversity: genetic erosion, ethnobotany and prospects. Genetic Resources and Crop Evolution, 50, 17-32.

Hore DK (2005) Rice diversity collection, conservation and management in Northeastern India. Genetic Resources and Crop Evolution, 52, 1129-1140.

Jiao AX, Wang YJ, Chen HC, Tan JY, Ruan RC (2015) Investigation of utilization and conservation on Kam sweet rice germplasm at Dong villages of Liping in Guizhou. Journal of Plant Genetic Resources, 16, 173-177. (in Chinese with English abstract) [焦爱霞, 王艳杰, 陈惠查, 谭金玉, 阮仁 超 (2015) 贵州黎平县侗族村寨香禾糯资源利用与保护 现状的考察. 植物遗传资源学报, 16, 173-177.]

Jiao WJ, Min QW, Cheng SK, Zhang D, Sun Y (2011) The emergy-based ecological footprint (EEF) of traditional agricultural areas in China: a case study of Congjiang County, Guizhou Province. Journal of Resources and Ecology, 2, 56-65.

Lei QY, Zhang WH, Sun J, Yang MX, Zhou JJ (2013) Traditional management and utilization of glutinous rice genetic resources in southeast Guizhou. Plant Diversity and Resources, 35, 195-201. (in Chinese with English abstract) [雷 启义, 张文华, 孙军, 杨敏贤, 周江菊 (2013) 黔东南糯 禾遗传资源的传统管理与利用. 植物分类与资源学报, 35, 195-201.]

Lei QY, Zhou JJ (2009) On the impact of prototypical ethnic cultures on plant diversity in southeast Guizhou. Journal of Southwest China Normal University (Natural Science Edition), 34, 88-92. (in Chinese with English abstract) [雷启义, 周江菊 (2009) 黔东南原生态民族文化对植物多样性的 影响. 西南师范大学学报(自然科学版), 34, 88-92.]

Leung H, Zhu YY, Revilla-Molina I, Fan JX, Chen H, Pangga I, Cruz CV, Mew TW (2003) Using genetic diversity to achieve sustainable rice disease management. Plant Disease, 87, 1156-1169.

Long CF, Kong B (2012) A research of Dong's traditional planting of sticky rice: a case study of Gaoqian Village of Congjiang County. Journal of Original Ecological National Culture, (4), 121-125. (in Chinese with English abstract) [龙 初凡, 孔蓓 (2012) 侗族糯禾种植的传统知识研究以贵州省从江县高任侗寨糯禾种植为例. 原生态民族文 化学刊, (4), 121-125.]

Lu BR (1998) Diversity of rice genetic resources and its utilization and conservation. Chinese Biodiversity, 6, 63-72. (in Chinese with English abstract) [卢宝荣 (1998) 稻种遗传 资源多样性的开发利用及保护. 生物多样性, 6, 63-72.]

Ma L, Yu XQ, Zhao FS (2010) Establishment of SSR finger print map of local rice varieties "He" in Guizhou. Southwest China Journal of Agricultural Sciences, 23, 5-10. (in Chinese with English abstract) [马琳, 余显权, 赵福胜 (2010) 贵州地方水稻品种 “禾”的SSR指纹图谱构建. 西南农业 学报, 23, 5-10.]

Pan YR, Long YX (2013) Nomenclature and classification of Kam sweet rice varieties: a case study of agricultural cognition of China's mountain peoples. Journal of Original Ecological National Culture, (1), 91-98. (in Chinese with English abstract) [潘永荣, 龙宇晓 (2013) 香禾糯品系命名与 分类的语言人类学考察—中国山地民族农业认知研究 系列之一. 原生态民族文化学刊, (1), 91-98.]

Pei SJ (2012) Ethnobotany and the sustainable use of biodiversity. Plant Diversity and Resources, 35, 401-406. (in English with Chinese abstract) [裴盛基 (2012) 民族植物学与 生物多样性的可持续利用. 植物分类与资源学报, 35 , 401-406.]

Pu K, Long YX (2012) The inheritance and protection of the genetic resources of the Dong nationality women and the glutinous rice - A case study of Huanggang Dong village in Liping County of Guizhou. Journal of Southwest University for Nationalities (Humanities and Social Science), 33, 28-35. (in Chinese with English abstract) [蒲琨, 龙宇晓 (2012) 侗族妇女与香禾糯遗传资源的在地传承保护-一 来自贵州黎平黄岗侗寨的田野个案研究. 西南民族大学 学报(人文社科版), 33, 28-35.] 
Sow M, Sido A, Laing M, Ndjiondjop MN (2014) Agro-morphological variability of rice species collected from Niger. Plant Genetic Resources, 12, 22-34.

Temudo MP (2011) Planting knowledge, harvesting agro-biodiversity: a case study of southern Guinea-Bissau rice farming. Human Ecology, 39, 309-321.

The Compilation Committee of Local Chronicles of Qiandongnan Miao and Dong Autonomous Prefecture (1993) Qiandongnan Miao and Dong Autonomous Prefecture Agriculture Chronicles, Guizhou People's Publishing House, Guiyang. (in Chinese) [黔东南苗族侗族自治州地方志编 纂委员会 (1993) 黔东南苗族侗族自治州农业志. 贵州 人民出版社，贵阳.]

The Editorial Board of The Integrity Guizhou History (2012) The integrity Guizhou History (Guizhou in Qing Dynasty). Contemporary China Publishing House, Beijing. (in Chinese) [贵州通史编委会 (2012) 贵州通史(清代的贵州). 当代中国出版社, 北京.]

Thrupp LA (2000) Linking agricultural biodiversity and food security: the valuable role of agrobiodiversity for sustainable agriculture. International Affairs, 76, 283-297.

Voeks RA (2007) Are women reservoirs of traditional plant knowledge? Gender, ethnobotany, and globalization in Northeast Brazil. Singapore Journal of Tropical Geography, 28, $7-20$.

Wang YJ, Wang YL, Sun X, Caiji ZM, Yang JB, Cui D, Han LZ (2016) Influence of ethnic traditional cultures on genetic diversity of rice landraces under on-farm conservation in southwest China. Journal of Ethnobiology and Ethnomedicine, 12, 51.

Wu XH (1981) Investigation report of "He" in Liping, Congjiang and Rongjiang counties. Guizhou Agricultural Sciences, (5), 65-70+64. (in Chinese) [吴祥厚 (1981) 黎平、从江、 榕江“禾”考察报告. 贵州农业科学, (5), 65-70+64.]

Wu YH, Pu XC, Yang CY, Long YX (2010) Classification of special rice varieties and its leaf-age cultivation model in Southeast Guizhou. Guizhou Agricultural Sciences, 38, 49-52. (in Chinese with English abstract) [吴元华, 浦选昌,
杨昌元, 龙宇晓 (2010) 黔东南禾稻类型分类及叶龄栽 培模式研究. 贵州农业科学, 38, 49-52.]

Yan QY (2008) A historic examination on crops planting from glutinous rice to indicia rice in the Southeast Guizhou. Ancient and Modern Agriculture, (3), 27-34. (in Chinese with English abstract) [严奇岩 (2008) 黔东南地区“糯禾改籼 稻”的历史考察. 古今农业, (3), 27-34.]

Yang L, Zhou DS, Zheng GY, Yang H, Shu N (2008) The original ecological farming culture in Qiandongnan Prefecture, Guizhou. Guizhou Agricultural Sciences, 36, 23-26. (in Chinese with English abstract) [杨黎, 周定生, 郑桂云, 杨华, 舒娜 (2008) 黔东南原生态农耕文化一一禾. 贵州 农业科学, 36, 23-26.]

Yang ZH (2014) A historical study of the growing of glutinous rice by the Dong ethnic group: a case study in southeast Guizhou Province. Journal of Yunnan Minzu University (Social Science), 31, 53-61. (in Chinese with English abstract) [杨筑慧 (2014) 侗族糯稻种植的历史变迁一以 以 黔东南黎、榕、从为例. 云南民族大学学报(哲学社会科 学版), 31, 53-61.]

Yu XQ, Jiang XH, Wu HB, Zhao DG, Fang XJ (2005) SSR genetic diversity of cold-tolerant native rice varieties in Guizhou. Southwest China Journal of Agricultural Sciences, 18, 1-4. (in Chinese with English abstract) [余显权, 蒋向 辉, 吴海滨, 赵德刚, 方宣钧 (2005) 贵州地方耐冷水稻 品种的SSR遗传多样性分析. 西南农业学报, 18, 1-4.]

Zheng XF, Fu Y, He XJ, Huang G, Yang AP, Yang LB (2010) Agronomic traits and classification of fragront rice germ plasm resource in Congjiang County. Seed, 29, 55-58. (in Chinese with English abstract) [郑晓峰, 付燕, 何宪江, 黄 刚, 杨安培, 杨利边 (2010) 从江香禾种质资源农艺性状 表现及分类. 种子, 29, 55-58.]

Zhu YY, Chen HR, Fan JH, Wang YY, Li Y, Chen JB, Fan JX, Yang SX, Hu LP, Leung H, Mew TW, Teng PS, Wang ZH, Mundt CC (2000) Genetic diversity and disease control in rice. Nature, 406, 718-722.

(责任编委：杨庆文 责任编辑：时意专)

\section{附录 Supplementary Material}

\section{附录1 侗族地区香禾糯品种与传统文化利用调查问卷}

Appendix 1 Questionnaire of varieties and traditional culture of Kam fragrant glutinous rice in the Dong regions http://www.biodiversity-science.net/fileup/PDF/w2017119-1.pdf 